\title{
Characterization Studies of Bentonite Barrier Interactions: Results From FEBEX-DP Bentonite Samples
}

\author{
Carlos F. Jove Colon ${ }^{1}$, Clay Payne ${ }^{2}$, Florie \\ CAPORUSCIO $^{3}$, ERIC COKER ${ }^{4}$, AND ANDREW KNIGHT ${ }^{5}$ \\ ${ }^{1}$ Sandia National Laboratories, Albuquerque, NM, USA, \\ 87123; cfjovec@sandia.gov; ${ }^{2}$ deceased; ${ }^{3}$ Los Alamos \\ National Laboratory, Los Alamos, NM, 87545, USA; \\ floriec@lanl.gov; ${ }^{4}$ Sandia National Laboratories, \\ Albuquerque, NM, USA, 87123; encoker@sandia.gov; \\ ${ }^{5}$ Sandia National Laboratories, Albuquerque, NM, USA, \\ 87123; aknigh@sandia.gov
}

Underground research laboratories (URLs) provide unique opportunities for field- and laboratory-scale experiments to evaluate engineered and natural barrier material interactions in deep geological repositories for nuclear waste disposal. Barrier material interactions at elevated temperatures are key to the performance analysis of disposal concepts as a result of thermally-driven processes. The FEBEX in-situ heater test at the Grimsel Test Site URL (Switzerland) was to simulate an horizontally-emplaced heat-generating waste canister $\left(100^{\circ} \mathrm{C}\right.$ maximum at the surface) surrounded by compacted bentonite blocks within a drift hosted in crystalline rock. This heater test provides $18+$ years of monitoring data, in addition to bentonite samples for analysis upon heater shutdown (FEBEX-DP, dismantling project). The focus of this work is on FEBEX bentonite samples collected spatially close and far from the heater surface, and analyzed using various characterization methods: X-ray diffraction (XRD), electron microscopy, X-ray fluorescence (XRF), X-ray CT scan, and thermal analyses. For example, the extent of swelling evaluated through XRD in bulk bentonite samples is similar for those located far from the heater surface. However, a slight decrease in the extent of swelling plus $\mathrm{Mg}$ enrichment was observed for samples close to the heater surface. Other analyses on compositional changes along bentonite-cement interfaces and the occurrence of microcracks in bentonite in an extracted core will be discussed.

Sandia National Laboratories is a multimission laboratory managed and operated by National Technology and Engineering Solutions of Sandia, LLC, a wholly owned subsidiary of Honeywell International Inc., for the U.S. Department of Energy's National Nuclear Security Administration under contract DE-NA0003525. 